\title{
OS RECURSOS HÍDRICOS E O TRÓPICO SEMIÁRIDO NO BRASIL
}

\author{
FLÁVIO RODRIGUES DO NASCIMENTO \\ Universidade Federal Fluminense
}

\section{Introdução}

Os recursos hídricos constituem um importante elemento físico na composição das paisagens, no esteio econômico e são elementos indispensáveis à vida, operando fenômenos da atmosfera inferior e litosfera, interferindo nas vidas animal e humana a partir da interação com os demais elementos dos seus ambientes de drenagem.

Parte da riqueza em recursos naturais acontece por conta das águas superficiais que têm suas demandas aumentadas no tempo e no espaço, em razão dos seus usos múltiplos, sobretudo em terras secas no Trópico Semiárido - como o semiárido brasileiro-, que sofre com secas cíclicas, com a distribuição das chuvas direcionando os regimes fluviais temporários e intermitentes. Nesse domínio, a gestão ambiental, com cerce na conservação dos recursos hídricos, não teve a devida atenção ao longo da história econômica dessa região, pois sofreu negligências nas políticas de desenvolvimento regional. Os rigores climáticos da mancha semiárida foram então magnificados pelo desenvolvimento de políticas niilistas e não procrastinatórias que corroboram para o crescimento da pobreza, êxodo rural, degradação ambiental e definhamento dos recursos hídricos.

Não obstante, as bacias de drenagens nordestinas apresentam dimensões e regimes diferenciados em razão de seu tamanho, condições ambientais, localização das nascentes dos exutórios e de uso/ocupação. Nesse contexto, o Trópico Semiárido Nacional, com toda sua complexidade ambiental, apresenta bacias intermitentes sazonárias, com relativa escassez hídrica espaço-temporal. Apresenta, portanto, dinâmica fluvial e potencialidades hidroambientais peculiares no bojo de um país que, por razão de sua tropicalidade, é predominantemente úmido.

A rigor, os recursos hídricos devem ser estudados em um contexto amplo de planejamento e gestão ambiental, atinando a bacia hidrográfica 
como unidade físico-territorial para que possam ser mais bem entendidos no domínio ciclo hidrológico como elemento fundamental à vida ou como recurso natural nas mais variadas etimologias da relação sociedade $\mathrm{x}$ natureza.

A discussão desse preâmbulo traz a questão dos recursos hídricos no contexto do Trópico Semiárido Nordestino. Destaca-se aqui a Bacia Hidrográfica Atlântico Nordeste, considerando a essencialidade de sua água e trópicos, e o Semiárido no Nordeste Brasileiro e plano de recursos hídricos como exemplo.

\section{A imprescindibilidade da água}

Como disse Rebouças: “a água é vida, água elemento vital, água purificadora, água recurso renovável, são alguns dos significados referidos em diferentes mitologias, religiões, povos, culturas, em todas as épocas" (Rebouças, 1997, p. 127). Sem dúvida, a água é um recurso essencial, seja como solvente universal - componente bioquímico dos seres vivos como meio de sobrevivência para várias espécies vegetais e animais, como elemento de valores sociais, culturais e estéticos, ou mesmo enquanto insumo na produção de serviços, de bens de consumo intermediários e finais - a exemplo da ampla diversidade de produtos agrícolas.

Segundo Nascimento, adicionalmente:

Pela necessidade que representa a água - como insumo produtivo, composição da paisagem, interferência em processos biogeoquímicos, para vida humana etc. -, os recursos hídricos são utilizados para múltiplos fins. Ocorre desde a retirada de água das coleções hídricas, promovendo perda entre derivação e o que retorna ao corpo hídrico, alterando sua quantidade, e perdas de qualidade por causa de finalidades subsequentes, a usos não consuntivos, quando não se tem necessidade de retirar as águas de suas coleções, isto é, o uso in situ.(...). (Nascimento, 2011a, p. 87)

Nesse contexto:

A água, recurso natural renovável, porém exaurível, é impactada por ações socioeconômicas que lhe conferem degradabilidade, reduzindo-lhe a higidez utilizável em intervalos espaciotemporais frequentemente mais curtos. As 
formas de utilização da água, ao contrário do que ocorre com a maioria de outros recursos naturais que desaparecem com o uso, produzem modificações sensíveis em seus aspectos quali-quantitativos. Desta forma, a contaminação dos recursos hídricos compromete a resiliência das águas e a geodinâmica das Bacias, competido para agravar o estado de conservação dos recursos naturais. (Nascimento, 2011b, p. 91)

Christofidis (2002) destaca que a escassez de água, face aos seus usos múltiplos e suas atividades produtivas, gera uma redução de sua disponibilidade, manifestada tanto na crise atual da saúde quanto na crise de médio prazo da alimentação básica, o que agrava os índices de qualidade de vida de hoje e das futuras gerações no contexto regional.

Em detalhe, um país tropical como o Brasil apresenta índices médios de chuva superiores a $1500 \mathrm{~mm} / \mathrm{ano}$, chegando até mesmo a ultrapassar os 2000mm, como na faixa equatorial Amazônica, com máximas superiores a 3000mm/ano. Entretanto, exceções acontecem no Nordeste Brasileiro, onde ocorre diminuição dessa média para $1.000 \mathrm{~mm}$ (CUNHA, 2001), ou mesmo para valores inferiores a 500mm. Nessa porção do território destaca-se uma mancha semiárida de caráter sazonal, sobressaindo o domínio morfoclimático das caatingas semiáridas, onde a política de construção de barragens coloca-se como saída para suplantar a questão da seca.

\section{Os Trópicos e o Nordeste Semiárido Brasileiro}

Os trópicos ficam a $23^{\circ} 27^{\prime}$ de latitude norte e sul do Equador imaginário. São áreas de alta pressão, onde os ventos sopram dessas latitudes para latitudes menores, ou seja, em direção à linha do Equador. Assim, o ar desce do alto da atmosfera, tornando-se mais quente e seco.

Para Ayoade (2002), nessa área as estações são definidas basicamente considerando-se a precipitação e a umidade relativa do ar. Conforme os totais de precipitação anual, os Trópicos podem ser subdivididos em dois subtipos: os Trópicos úmidos, com precipitação maior que $600 \mathrm{~mm} /$ ano e os Trópicos secos, onde as precipitações não ultrapassam tais limiares. Além disso, correspondem a cerca de $40 \%$ da superfície da terra, compreendendo grande parte dos países pobres, agrícolas, com baixa renda per capita, ocupando na divisão internacional do trabalho o entreposto de celeiros agrícolas e fornecedores de matériaprima de ordem em geral, como o caso nacional. 
No Brasil, desconsiderando a região Norte e a parte equatorial da região Centro-Oeste, o restante da região, juntamente com as regiões Sudeste e Nordeste, a rigor, são atingidas pelo clima tropical típico, que se constitui como um complexo influenciado pela dinâmica atmosférica de diversos sistemas e fatores geográficos. Desta feita, podem ser destacadas algumas características do clima tropical no espaço nacional no Quadro 1:

\begin{tabular}{||c||l||}
\hline \multicolumn{1}{|c||}{ Características } & \multicolumn{1}{|c||}{ Papel no espaço brasileiro } \\
\hline \hline $\begin{array}{l}\text { Temperaturas médias superiores a } 18^{\circ} \mathrm{C} \\
\text { e diferenças sazonais marcadas pelo } \\
\text { regime de chuvas. }\end{array}$ & Ocorrem em 95\% do território. \\
\hline \hline $\begin{array}{l}\text { Amplitude térmica inferior a } \quad 6^{\circ} \mathrm{C} \\
\text { (isoterma). }\end{array}$ & $\begin{array}{l}\text { Registrado, aproximadamente, desde o } \\
\text { extremo norte até o paralelo de } 20^{\circ} \text { de latitude } \\
\text { sul. }\end{array}$ \\
\hline \hline $\begin{array}{l}\text { Circulação atmosférica controlada pela } \\
\text { ZCIT, baixas pressões (doldrums), } \\
\text { alísios e altas pressões subtropicais. }\end{array}$ & $\begin{array}{l}\text { Atinge quase todo o país, exceto ao sul do } \\
\text { Trópico de Capricórnio e onde a ação da } \\
\text { frente polar se faz sentir mais intensamente. }\end{array}$ \\
\hline \hline $\begin{array}{l}\text { Cobertura vegetal que vai do deserto } \\
\text { quente à floresta ombrófila, passando } \\
\text { pela savana. }\end{array}$ & $\begin{array}{l}\text { Não existindo desertos quentes, a floresta } \\
\text { ombrófila e as savanas cobriam 94\% do } \\
\text { território brasileiro. }\end{array}$ \\
\hline \hline $\begin{array}{l}\text { Regimes fluviais controlados pelo } \\
\text { comportamento da precipitação. }\end{array}$ & $\begin{array}{l}\text { Verificando em todas as bacias hidrográficas, } \\
\text { exceto a Amazônica, onde alguns afluentes } \\
\text { estão em função da fusão das neves andinas. }\end{array}$ \\
\hline \hline
\end{tabular}

Quadro 1 - Importantes características de ambientes tropicais e seu papel no Brasil. Fonte: Adaptado de Conti e Furlan (1995).

Especificamente, o Nordeste brasileiro representa uma região geoeconômica e ambiental complexa e diversificada no domínio dos trópicos. Dentro de uma Geografia intertropical, esta região resguarda praticamente todos os tipos de paisagens verificadas no Brasil, onde se destaca o domínio morfoclimático das caatingas que capeiam os sertões semiáridos. Dessa diversidade, decorrem formas e maneiras complexas das relações sócio-espaciais x geoambientais, onde o semiárido pode ser individualizado no contexto regional conforme suas peculiaridades. E a rigor, o Trópico Semiárido abrange quase um quinto do território nacional com nove Estados, somados com a porção norte de Minas Gerais, numa área de 1.135.245,2 $\mathrm{km}^{2}$ (Figura 02). 


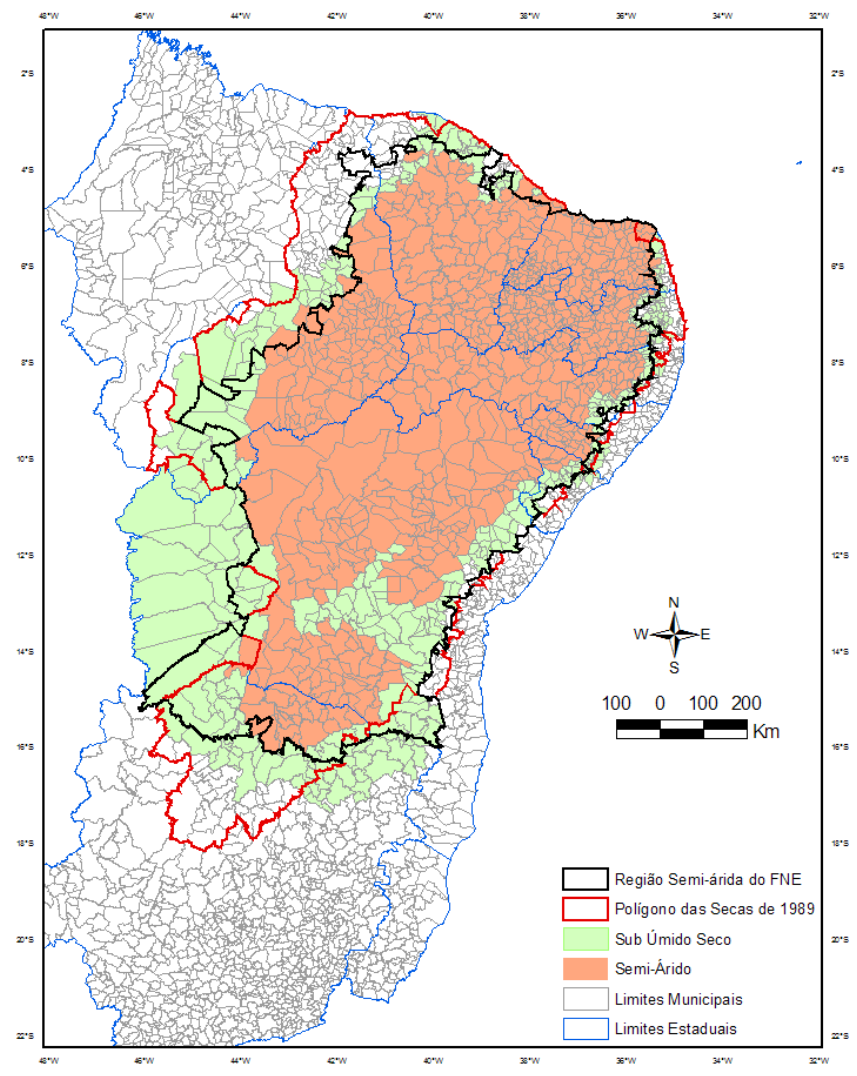

Figura 2 - Nordeste brasileiro: Semiárido do FNE, Polígono das Secas e a Redelimitação do semiárido. Fonte: Ministério da Integração Nacional, 2005.

$\mathrm{Na}$ verdade, o Nordeste semiárido brasileiro constitui-se como um dos três núcleos de regiões semiáridas na América do Sul, inseridos num contexto de uma área continental predominantemente úmida. Os núcleos de semiaridez são: a diagonal arréica seca do Cone Sul, que ultrapassa a cadeia andina, estendendo-se em direção a $5^{\circ}$ de latitude sul ao longo da Argentina, Chile e Equador; a região Guajira, na Venezuela e na Colômbia, em regiões semiáridas na fachada caribenha, no extremo noroeste do bloco continental sul-americano; e o nordeste seco do Brasil, província fitogeográfica das caatingas, com temperaturas médias/ano elevadas e constantes.

As similitudes das regiões semiáridas envolvem sempre aspectos climáticos, hídricos e fitogeográficos, como é passível de verificação a 
partir dos índices de umidade baixos; da escassez relativa de chuvas anuais; da irregularidade pluviométrica ao longo dos anos; dos longos períodos de carência hídrica; dos solos com problemas físicos e químicos, como os parcialmente salinos ou carbonáticos; e da ausência de perenidade fluvial, principalmente em relação às drenagens autóctones, conforme lembrado por Ab'Saber (1999).

Registre-se que, desde o período imperial, as discussões a respeito das características fisiográficas e, principalmente, sobre as contingências climáticas e de vulnerabilidade das secas no Nordeste Brasileiro, foram mais políticas que ecológicas. Para termos uma ideia, a própria criação da área conhecida como o Polígono das Secas ocorreu por uma aproximação da área nuclear do domínio morfoclimático dos sertões secos das caatingas semiáridas (Ab'saber, 1999), a partir de isoietas, e foi delimitado por decreto Lei $\mathrm{N}^{\circ} 1348$ de 10/02/1951 em uma área de 936.993km².

Enquanto esboço geral dos problemas geoambientais encontrados no Nordeste seco, favorecedores de instabilidade ambiental, baixa sustentabilidade ambiental e, proporcionalmente, uma alta vulnerabilidade de seus domínios ecológicos (Souza, 2000), podemos destacar os seguintes aspectos ecofisiográficos (Quadro 2).

\begin{tabular}{||c||c||}
\hline $\begin{array}{c}\text { Condições } \\
\text { geoambientais }\end{array}$ & \multicolumn{1}{|c|}{ Fatores de vulnerabilidade geoambiental } \\
\hline \hline $\begin{array}{c}\text { Aspectos } \\
\text { Termopluviométricos }\end{array}$ & $\begin{array}{l}\text {-Expressiva extensão da área semiárida, com isoietas não } \\
\text { expressivas }- \text { da ordem de } 800 \mathrm{~mm} \text { média/ano - onde as chuvas } \\
\text { são concentradas em poucos meses e há uma irregularidade no } \\
\text { tempo e no espaço. Além de existirem elevadas temperaturas } \\
\text { médias por ano }\left(22^{\circ} \mathrm{C} \text { a } 28^{\circ} \mathrm{C}\right) \text {, com pouca variação entre as } \\
\text { áreas e insolação muito alta: cerca de } 2.800 \text { horas por ano, } \\
\text { considerando } 750 \text { mm de precipitação anual. } \\
\text {-As taxas de evapotranspiração são elevadas por conta dos } \\
\text { coeficientes térmicos elevados durante o ano e da pequena } \\
\text { quantidade de água disponível para as plantas. }\end{array}$ \\
\hline $\begin{array}{c}\text { Aspectos } \\
\text { Hidrológicos }\end{array}$ & $\begin{array}{l}\text { Pequeno potencial de natureza hidroenergética, em função da } \\
\text { larga predominância de rios intermitentes sazonários. Este regime } \\
\text { caracterizado pelo ciclo hidrológico, que pode variar } \\
\text { anualmente devido a eventos como El Nino e La Nina, com } \\
\text { drásticas consequências à pecuária e à agricultura. Enquanto } \\
\text { derivação, o potencial hidrogeológico é modesto e restrito a } \\
\text { fraturas cristalinas e manchas aluviais. }\end{array}$ \\
\hline \hline
\end{tabular}




\begin{tabular}{||c||l||}
\hline $\begin{array}{c}\text { Aspectos do } \\
\text { Potencial Agrário }\end{array}$ & $\begin{array}{l}\text { Proporção diminuta de terras simultaneamente favorecidas de } \\
\text { potencialidades edafo-climáticas e com limitações de ordem } \\
\text { topográfica com relevos montanhosos de serras cristalinas; } \\
\text { historicamente a uma estrutura agrária rígida. }\end{array}$ \\
\hline \hline $\begin{array}{c}\text { Condições } \\
\text { Ecodinâmicas e } \\
\text { Vulnerabilidade } \\
\text { Ambiental em geral }\end{array}$ & $\begin{array}{l}\text { Ambiente de transição com tendência à instabilidade nas áreas } \\
\text { mais degradas; vulnerabilidade moderada a alta; evidências de } \\
\text { desertificação em efeitos areolares. }\end{array}$ \\
\hline
\end{tabular}

Quadro 2 - Esboço geral dos problemas geoambientais do Nordeste Seco, especificamente no Ceará. Fonte: Jatobá et al., (1996), SOUZA (2000), CRUZ et al., (2005) e Nascimento (2006).

Os espaços semiáridos apresentam maior abrangência físicoterritorial regional que os demais espaços naturais que conformam e estruturam o Nordeste (Brasil, 2004). Isso contribuiu para que fossem forjadas ideias erradas sobre as dificuldades dos problemas ambientais (físicos e humanos) atrelados às secas e associados à dimensão da declamação oficial desse fenômeno (Rebouças, 1997).

Em grande escala, o clima é quente e relativamente seco, com inverno seco, quase sem chuva durante cerca de cinco a oito meses ao ano. A partir do verão, ocorrem as chuvas de quatro a sete meses, denotando grandes e fortes instabilidades no tempo e no espaço. As altas variações interanuais de precipitação comprovam o caráter climaticamente transicional da região, onde os valores de coeficiente podem ser designados como efeito de borda, presente nas áreas marginais dos desertos e nos domínios semiáridos em geral (Conti, 1999).

A escassez pluviométrica é acentuada nas depressões sertanejas periféricas, sobretudo nas vertestes a sotavento dos maciços residuais, como em: Queimada Nova, vertente ocidental da Serra dos Dois Irmãos (PI) com 398 mm; e nos vales do Pajeú e Moxotó, em Inajá (394 mm), Moxotó (429,9 mm) e Floresta $(501,3$ mm). Na depressão San-franciscana, a estiagem estende-se por até onze meses. Todavia, a localidade mais seca do semiárido é Cabaceiras-PB, com 336 mm/ano. No Raso da Catarina, no médio alto Vaza Barris, encontra-se um dos trechos mais secos do Nordeste, com pluviometria média de 300 a $400 \mathrm{~mm}$, além de registrar o mais baixo índice da história, $311 \mathrm{~mm} / \mathrm{ano}$, na localidade de Quinjique. 
Grosso modo, as áreas mais afetadas pelas secas são as que estão sob domínio da Zona de Convergência Intertropical (ZCIT). Em grande parte, o semiárido apresenta certa homogeneidade física, sendo destacado o âmago da semiaridez com probabilidade de secas de 81 a 100\% (Brasil, 2004). A maior área de incidência de estiagem tem em seu interior reduções concentradas no Cariri cearense, Serra de Triunfo em Pernambuco e no Planalto da Borborema na Bahia. Ao leste, vai reduzindo em direção ao litoral oriental. Ao sul, essa incidência varia no intervalo mínimo de 0-20\%, desde o sul baiano para além nordeste, em Minas Gerais.

Nessa acepção, a Bacia do Atlântico Nordeste abrange uma das regiões mais pobres da Federação, pois há nas contingências do semiárido um forte entrave ao aproveitamento dos recursos naturais, com destaque aos hídricos. As condições climáticas observadas nessa bacia apresentamse no cinturão de climas áridos e semiáridos tropicais, e subtropicais das terras. O clima semiárido predominante está intimamente relacionado aos princípios básicos de circulação atmosférica no Nordeste. Essa bacia, por encontrar-se nos limites da faixa equatorial e pela não-incidência do Anticiclone do Atlântico Sul, está submetida a intenso e permanente regime térmico ao longo do ano, sendo as variações dionoturnas mais expressivas (Rodriguez e Silva, 2001).

Ao longo do ano, a ZCIT mantém-se acima da faixa equatorial. Origina-se da convergência de ventos alísios de nordeste e sudeste. Ocorre durante o verão (outono no hemisfério sul), constituindo-se como o principal causador de chuvas no Nordeste setentrional. Conforme o Ministério da Integração Nacional (2005), as precipitações registradas apresentam médias de $800 \mathrm{~mm} / \mathrm{ano}$, com acréscimos para as serras úmidas e litoral em torno de $1.200 \mathrm{~mm} /$ ano e com expressivos decréscimos para os sertões, com $400 \mathrm{~mm} /$ ano. A evapotranspiração mantém anualmente o impressionante índice de $1.700 \mathrm{~mm}$, que chega a ser sobremaneira influenciada com forte insolação anual de até 2.800 horas/ano.

Principalmente nos sertões, onde os suprimentos de água são limitados e, como resultado, há baixa produtividade de recursos naturais, a intermitência dos cursos d'água provoca recessão e descarga nula durante os meses de estio que se prolongam ao longo do ano. Por isso, é importante o gerenciamento da vazão hídrica dos reservatórios e dos rios durante o ano, principalmente na estação chuvosa e em consonância com a redução de conflitos pelos usos múltiplos da água e acesso a terra. 
A Bacia do Atlântico Nordeste, com seus rios intermitentes, é caracterizada como a de regiões subdesérticas, pois é extensivamente drenada por redes hidrográficas exorréicas, hierarquizadas por densas e variadas ordens tributárias. Os aspectos fluviais, em grande parte, exibem rios autóctones, como o Jaguaribe e Acaraú, no Ceará, e o Piranhas, na Paraíba e no Rio Grande do Norte, ou mesmo alóctone, como no caso do Rio São Francisco, abastecido por áreas de drenagem extrarregionais, com dinâmica climato-hidrológica distinta daquela verificada no semiárido.

Convém salientar que ideias equivocadas sobre as dificuldades dos problemas ambientais atrelados às secas, associam-se à dimensão da declamação oficial do fenômeno. Com os aspectos arrolados acima, justifica-se considerar um redimensionamento do semiárido que, longe de ser homogêneo, constitui-se como diversificado e complexo, prova disso é a existência dos sertões.

\section{Bacia Hidrográfica: Unidade Ambiental de Planejamento}

Os recursos hídricos devem ser avaliados em um contexto sócioespacial amplo, transcendendo a uma visão exclusivamente limnológica. As bases científicas para o conhecimento de um sistema aquático para a realização de prognósticos da qualidade hídrica e sua recuperação e manejo só serão possíveis através de um instrumento que viabilize estudos integrados dos aspectos ambientais, os quais emanam da concretude e das possibilidades analíticas do conceito de Bacia Hidrográfica, destacado por Paula, como sendo "sistemas terrestres e aquáticos geograficamente definidos, compostos por sistemas físicos, econômicos e sociais, onde se conjugam questões ambientais" (Paula et al.,1997, p. 257).

Uma bacia hidrográfica denota características geoambientais, formando uma unidade natural indissociável e interatuante. É um sistema complexo - dado o número de elementos e variáveis -, em que as relações mútuas entre os seus componentes estruturais possibilitam a análise integrada do meio ambiente, permitindo uma acurada avaliação dos seus aspectos, quer físicos, quer econômicos e sociais. Por isso, deve ser concebida como sistema "multicomposto" que inclui desde a água aos elementos do potencial geoecológico sobrepostos, dialeticamente, por aspectos sócio-políticos e econômicos.

Devido à essencialidade que a água abarca, a bacia hidrográfica frequentemente é utilizada como referencial geográfico para o 
planejamento, manejo e aproveitamento de recursos naturais. Assim, essa entidade ecológica tem se tornado uma unidade básica ao gerenciamento ambiental, isto é, um recurso natural como âncora dos "processos regionais de desenvolvimento". Além das instituições que trabalham com recursos hídricos, a comunidade, a propriedade privada ou os municípios por ela banhados são responsáveis por sua sustentabilidade. Desta feita, ao gerenciar a água, há a obrigação indireta de gerenciar diversos processos ambientais e planejar o espaço territorial, respeitando os parâmetros de sustentabilidade ambiental dos sistemas naturais remanescentes.

Todavia, é inquestionável que qualquer uso dispersivo da água afeta o equilíbrio hidrológico da própria bacia, sobretudo em regiões de alta vulnerabilidade ambiental, como os sertões. Amiúde, a vocação econômica, os aspectos geoecológicos e o uso cultural de cada bacia tornam-na singular. Por esses fatores, a bacia hidrográfica é a unidade natural mais adequada para ao gerenciamento dos recursos hídricos. No entanto, a administração de uma bacia não é uma tarefa fácil. Apenas um pequeno detalhe nesse domínio: além de unidades naturais, as mesmas ainda sofrem injunções enquanto unidades político-administrativas.

Convém registrar que a análise integrada do ambiente detém importante papel na compreensão das relações sociedade/natureza, demandando avaliações holísticas de tais condições, com valorização de preceitos físico-geográficos, com destaque aos processos hidrológicos (Bachelor e Wallace, 1995).

Contudo, muitos fatores concorrem para se destacar a bacia hidrográfica como unidade referencial de planejamento e gestão ambiental, com prioridade aos recursos hídricos, (MMA, 1997; Nascimento, 2006). Finalmente, é possível registrar que:

Em seu âmbito, é possível subsidiar o desenvolvimento de parcerias e de resolução de conflitos para usos dos recursos naturais; como ainda analisar a degradação ambiental a partir de sistemas fluviais;

Estimula e permite a participação popular, democraticamente, com relação ao poder público, Organizações Não Governamentais (ONG's) e entidades privadas, descentralizando os trabalhos de conservação e de proteção ambiental, e estimulando as integrações comunitária e institucional;

Comporta-se como uma unidade fisiográfica indissociável passiva de ser geocompartimentada em trabalhos geoambientais integrados; 
$\checkmark \quad$ Possibilita uma forma racional de organização de banco de dados, além de garantir alternativas para o uso dos mananciais e de seus recursos;

$\checkmark \quad$ Evidencia o estado de degradação ambiental pela eutrofização, bem como pelo assoreamento dos corpos hídricos;

$\checkmark \quad$ Apresenta um arcabouço jurídico-ambiental bem consubstanciado (Lei ${ }^{\circ}$ 9.433/97).

\subsection{Bacias intermitentes sazonais: Bacia do Atlântico Nordeste}

$\mathrm{Na}$ questão dos recursos hídricos, por compreender o bens mais valiosos neste século e de importância para todos os países, destaca-se o Brasil que é o detentor do maior volume de águas doces do planeta, arranjando, segundo Cunha (2001) uma das mais extensas e densas redes hidrográficas do mundo, com descarga média total da ordem de 5.619 $\mathrm{km}^{3} / \mathrm{ano}$, ou seja, aproximadamente $14 \%$ dos $41 \mathrm{mil} \mathrm{km} 3 /$ ano de deflúvio dos rios no mundo. Esse montante chega a ser reduzido proporcionalmente na região nordestina seca.

Filho et al. (1994), baseados no Plano de Aproveitamento Integrado dos Recursos Hídricos do Nordeste do Brasil de 1980 (PLIRHINE), promovido pela Superintendência de Desenvolvimento do Nordeste (SUDENE), consideraram no Nordeste do Brasil 24 Unidades Hidrográficas de planejamento, correspondentes a uma bacia ou a um conjunto de bacias como modo de tratamento das secas, da degradação/desertificação e do desenvolvimento regional. Dessas, 19 são compostas por rios intermitentes sazonários, quais sejam: Acaraú-Coreaú (30.500 km²); Curu (11.500 km²); Fortaleza $\left(14.700 \mathrm{~km}^{2}\right)$; Jaguaribe (72.000 km²); Apodi-Mossoró (15.900 km²); Piranhas-Açu (44.100 km²); Bacia do Leste Potiguar (24.440 km²); Bacia Oriental da Paraíba (23.760 $\mathrm{km}^{2}$ ); Bacia Oriental de Pernambuco $\left(25.300 \mathrm{~km}^{2}\right)$; Bacias Alagoanas $\left(17.100 \mathrm{~km}^{2}\right)$; São Francisco $\left(487.000 \mathrm{~km}^{2}\right)$; Vaz-Barris $\left(22.300 \mathrm{~km}^{2}\right)$; e Itapicuru-Real $\left(46.100 \mathrm{~km}^{2}\right)$. Segundo Cunha (2001), o Departamento Nacional de Águas e Energia Elétrica (DNAEE) classifica o Brasil em oito bacias hidrográficas: Amazônica; Tocantins; Atlântico Sul, trecho norte/nordeste; São Francisco; Atlântico Sul, trecho leste; Paraguai/Paraná; Uruguai; e Atlântico Sul, trecho sudeste. No entanto, devido às particularidades de cada bacia em função das suas características ambientais dominantes - como a distribuição espaço-temporal das precipitações, fatores estruturais refletindo na importância e características de drenagem e dissecação do Planalto Brasileiro (um importante dispersor 
de drenagem), tipo de solo e as formas de uso e ocupação -, aquela autora as reclassificou a partir de dez unidades, dentre as quais pode ser destacada a Bacia do Atlântico Nordeste, que comporta regimes fluviais temporários e intermitentes (semiáridos).

Essa bacia apresenta uma área de $953 \mathrm{mil} \mathrm{km}^{2}$, com rios intermitentes sazonais que vertem para o Oceano Atlântico. Administrativamente drena por completo as áreas dos estados do Maranhão, Piauí, Ceará, Rio Grande do Norte e Paraíba. E, parcialmente, o Amapá, Pará, Pernambuco e Alagoas. Destacam-se como drenagem principal os rios Pindaré, Grajaú Mearim e Itapecuru, que vão ter com o Golfo Maranhense, e o Rio Parnaíba. Desconsiderando esses rios, que são perenes, pode-se afiançar que os demais drenam setores concentrados e difusos do semiárido nordestino, marcando entre os interflúvios sertanejos paisagens que sofrem com as vicissitudes climáticas e com a vulnerabilidade das secas, intensificando a instabilidade do meio físico e a distribuição no tempo e no espaço das chuvas e das águas superficiais, promovendo a formação de rios que cortam durante as estiagens.

Foram registrados valores de $600 \mathrm{~mm}$ anuais de chuvas no centro da Bacia do Atlântico Nordeste, aumentado para suas extremidades. Embora a chuva média seja de $1.328 \mathrm{~mm} / \mathrm{ano}$, o regime fluvial é semiárido, com vazão média de $5,7 \mathrm{l} / \mathrm{s} / \mathrm{km}^{2}$. As enchentes ocorrem na quadra chuvosa de verão-outono, e as vazantes na primavera ou no verão. No Maranhão, o regime tropical austral mostra-se perene, com enchentes no outono e vazante na primavera, que marcam o regime fluvial (Cunha, 2001).

Contudo, segundo Rebouças (1997), a crise de água no país, sobretudo no Nordeste, decorre no geral de um crescimento rápido e desordenado das demandas; degradação da qualidade dos mananciais, normalmente utilizados em níveis inimagináveis; e pela baixa eficiência dos serviços de saneamento básico. Nessa perspectiva, as potencialidades e limitações hidroambientais merecem destaque especial como alternativa de acesso a água.

\subsection{1 - Potencialidades Hidrogeológicas}

O potencial hidrogeológico nas bacias semiáridas usualmente constitui reservatórios subterrâneos diversos, desde zonas fraturadas ou de rochas intemperizadas do substrato geológico pré-cambriano, até depósitos quaternários aluviais, com dimensões variadas, geralmente não grandes, contendo volumes de água acumulados que podem remontar às origens de 
suas formações geológicas. Sua disponibilidade pode ter potencial hídrico ainda não usado pelos homens, podendo as reservas serem acrescidas se alguma demanda socioeconômica assim exigir, comportando-se como alternativa hídrica.

A grande maioria das bacias sertanejas estão sobre embasamento cristalino, uma vez que suas águas subterrâneas são alimentadas pelas chuvas ou por rios que, em função de uma permoporosidade insignificante, as taxas são ínfimas. Ademais, a deficiente alimentação e a falta de exutórios importantes tornam as condições hidrogeológicas mais exíguas. Em miúde, a capacidade de armazenamento d'água subterrânea é fornecida por arranjos estruturais localizados nos contatos geológicos por falhas e no manto de alteração, pois são favoráveis ao armazenamento de águas subterrâneas. As fissuras e fraturas, enquanto porosidade secundária, por onde a água circula, apresenta condutibilidade hidráulica não a partir de porosidade primária das rochas, como no caso de aqüíferos clásticos, mas pelos efeitos dos componentes estruturais alimentados por precipitação atmosférica, rede hidrográfica e as aluviões (Gonçalves et al., 1984).

Portanto, de um modo em geral, as águas subterrâneas do domínio cristalino são limitadas. A vazão média em poços tubulares é ínfima, da ordem de $5 \mathrm{~m}^{3} / \mathrm{h}$ e salinidade média da ordem de $2 \mathrm{mil} \mathrm{mg/l}$, o que pode comprometer sua potabilidade (Rebouças, 2002). Dada à falta de fiscalização das atividades de perfuração e uso de poços, estima-se que no Nordeste seco existem aproximadamente $50 \mathrm{mil}$, sendo que pouco mais de 20 mil estão em operação por razões técnicas e/ou políticas (Rebouças, 1997). Entretanto, com índices de evaporação críticos na região, que favorecem a um balanço hídrico deficitário, as águas subterrâneas encontram-se mais bem protegidas, com uma parcela de perda hídrica consideravelmente menor do que aquela perdida por mananciais de superfície.

Entre aquíferos aluvionar, sedimentar e fissural a CPRM (1998) cadastrou no Estado do Ceará, a título de exemplificação, 13.394 poços. Desses, $6.001(50,1 \%)$ são públicos e $5.887(49,15 \%)$ são privados, sendo 316 (2\%) provenientes de fontes naturais, $1.093(8 \%)$ são amazonas e 11.888 são tubulares (92\%). Para fins de uso, apresentam o seguinte funcionamento: 1.650 (12,6\%) estão ativados; 2.339 (17,9\%) desativados; $1.469(11,3 \%)$ não estão instalados; e os restantes $7.781(58,14 \%)$ servem para usos de irrigação, dessedentação animal, abastecimento público e de fazendas. 
Esses poços comportam-se em reservar hídricas que podem ser importantes principalmente durante as estiagens para o aproveitamento prioritário humano, dessedentação de animais e outros. As demandas para tal fim devem ser garantidas em qualquer cenário considerável, conservando e distribuindo equilibradamente aportes desse recurso vital em quantidades e qualidades mínimas, em consonância com as coleções hídricas de superficiais em planos de gerenciamento de bacias hidrográficas.

\section{2 - Gestão de Bacias Hidrográficas e Alterações Ambientais}

Os rios do intermitentes, no período de vazante, atingem o mar tratando-se de um dos fatores de originalidade dos sistemas hidrográficos e hidrológicos regionais que, ao contrário de outras regiões semiáridas do mundo onde drenagens convergem para depressões fechadas, os rios dessa região vão ter com o Atlântico (Rebouças, 2002). Por isso, no Nordeste semiárido os rios são de caráter intermitente - à exceção dos perenizados por açudagens/barramentos -, com drenagem exorréica que, em grande escala, não permitem a formação de solos originalmente salinos, principalmente nas vertentes e interflúvios. Os sais dissolvidos da litologia cristalina, predominante na meso-estrutura, e aqueles provenientes das chuvas carregadas de águas evaporadas do oceano vão ter com o nível de base após arraste pelo fluxo hídrico das torrentes.

O escoamento fluvial e as reservas terrestres, implicantes na dinâmica ecossistêmica que forjam os geoambientes, são influenciados pelos elementos físico-ambientais: clima; natureza do terreno e litotipos; geologia-geomorfologia; unidades vegetacionais e uso/ocupação da terra. As intervenções humanas incidentes sobre os recursos hídricos apresentam efeitos ambientais, diretos e indiretos (Ebisemiju, 1987) no exutório. Segundo o autor citado, diretamente, a retificação, a dragagem do rio e os barramentos indevidos alteram as condições naturais dos rios e concorrem para as mudanças indiretas, o desmatamento, a impermeabilização de superfícies e para as mudanças do uso da terra. Esses fatores em conjunto podem provocar modificações nas propriedades físicas e estruturais dos solos, na precipitação e na temperatura.

Por conta da crescente demanda por água para consumo humano e para atividades produtivas, há que se adequar a relação água/sociedade (cada habitante da bacia hidrográfica) a um processo de gerenciamento integrado, o qual Rebouças (1997) chamou de disponibilidade hídrica 
social dos rios. Porque à proporção que a demanda por água aumenta, alcançando determinados níveis de disponibilidade social - disponibilidade per capita -, a demanda por gerenciamento faz-se fundamental. Em nível global, a Tabela 2 afere sobre o assunto os seguintes preceitos:

\begin{tabular}{|c|l|}
\hline $\begin{array}{c}\text { Demanda de águas } \\
\text { renováveis: vazões totais } \\
\text { médias (fluxos superficial + } \\
\text { subterrâneo) }\end{array}$ & Grau de necessidade de gestão e investimentos \\
\hline$\leq 5 \%$ & $\begin{array}{l}\text { Baixo: água como bem livre, sob respeito ambiental e } \\
\text { legal. }\end{array}$ \\
\hline $5 \%$ a $10 \%$ & $\begin{array}{l}\text { Moderado: pode ocorrer a necessidade a partir de um } \\
\text { pequeno investimento para solucionar os conflitos } \\
\text { locais. }\end{array}$ \\
\hline $10 \%$ a $20 \%$ & Alta: indispensável. Investimentos médios. \\
\hline$>20 \%$ & $\begin{array}{l}\text { Altíssima: situação crítica. Investimento e } \\
\text { gerenciamento intensivos. }\end{array}$ \\
\hline
\end{tabular}

Tabela 2 - Necessidade de gerenciamento dos recursos hídricos conforme disponibilidades per capita. Fonte: Elaborado com base em Falkenmark e Lindh, 1976 in Rebouças (1997).

Enquanto na maioria dos países desenvolvidos o consumo per capita de água oscila entre $24 \%$ e $92 \%$, em quase todo o Nordeste brasileiro esses valores per capita são inferiores a $10 \%$ dos potenciais de águas dos rios (Rebouças, 1997), portanto existe necessidade de gerenciamento hidroambiental. A título de exemplificação, destacando cálculos específicos para o Estado do Ceará, a partir dos dados levantados para o Nordeste por Rebouças, deduz-se que esse estado tem uma demanda média anual de 16,25\%, e futura (até 2020) de 23,25\%. Embora regionalmente as bacias do interior diminuam esses índices, a média foi elevada por conta da alta demanda da Região Metropolitana de Fortaleza (RMF). Conforme dados da Tabela 2, advoga-se que para a atualidade há uma necessidade de gerenciamento alto, devido à degradabilidade de investimentos face à crescente demanda. 
Contudo, a água é um recurso fundamental no processo de estruturação e organização socioeconômica, política e cultural do espaço geográfico cearense. Outrora, a água era um produto livre, hoje, a ciência e a técnica exploram-na sob a lógica mercadológica, influenciando sua qualidade e distribuição, estocando, calculando aportes desse recurso (Sampaio, 2005).

A importância de destacar o Ceará nesse contexto advém de sua situação privilegiada e avançada no que se refere à gestão de bacias e ao gerenciamento de recursos hídricos no contexto nacional e da América Latina. Esse estado, São Paulo e o Paraná representam as Unidades Federativas melhor arquitetadas quando se tratam de trabalhos sobre recursos hídricos, com um sistema instituição consolidado, com comitê e consórcios historicamente atuantes, bem como por estudos sólidos por parte dos governos, universidades e institutos de pesquisas.

Sendo assim, priorizando-se estabelecer o uso racional da água como incremento da produtividade econômica e abastecimento público (como prioridade) em face da escassez hídrica, em 1992, foi aprovado no Ceará o Plano Estadual de Recursos Hídricos. Tal plano deu-se anteriormente à Lei 9.433/1997 (Lei das Águas), colocando esse Estado como um dos primogênitos no tratamento dos recursos hídricos no Brasil em termos de planejamento. Em 1996, foi criada a cobrança pelo uso da água, embora essa decisão esteja ainda em processo de discussão com os próprios comitês de bacias (Sampaio, 2005) que, por sinal, têm poderes deliberativos e normativos, assumindo e decidindo sobre as consequências positivas e negativas resultantes da gestão dos recursos naturais, preferencialmente os hídricos, ao passo que agregam custos inevitáveis ao acesso à água (Nascimento, 2005).

$\mathrm{Na}$ realidade, porém, o diapasão tem sido privilegiar o setor industrial, agroindustrial e de perímetros irrigados, e a RMF, em detrimento de outros setores produtivos com destaque aos pequenos $\mathrm{e}$ médios trabalhadores rurais, entre ranços e avanços e regiões no interior do Estado. Os governos estaduais do Ceará, desde a última década até o ano de 2006, a partir de uma mesma concepção partidária e política, vêm desenvolvendo o Programa Águas do Ceará para o trato com os recursos hídricos, considerando para seu planejamento onze bacias hidrográficas (Figura 3).

Esse programa destacou um elenco de projetos e subprogramas voltados à política de águas, a citar, o Projeto de Desenvolvimento Urbano e Gestão dos Recursos Hídricos do Estado do Ceará- PROURB - CE, que 
implantou múltiplas ações dos poderes público, estadual e municipal no desenvolvimento de áreas estratégicas de infraestrutura urbana e suporte hídrico para o desenvolvimento estadual, com destaque à regularização do abastecimento de água para seus usos múltiplos, através do aumento da oferta e do gerenciamento (Rodrigues, 1999). Outros programas estão em fase de implementação junto ao Governo Federal e instituições financeiras internacionais para otimizar o manejo das $(\mathrm{BH})$ do território cearense, respectivamente: PROÁGUA - Programa de Desenvolvimento Sustentável do Semiárido Brasileiro; PROGERIRH - Programa de Gerenciamento e Integração dos Recursos Hídricos; PROASIS - Programa de Águas Subterrâneas; PRODHAM - Programa de Desenvolvimento Hidrogeoambiental das Bacias.
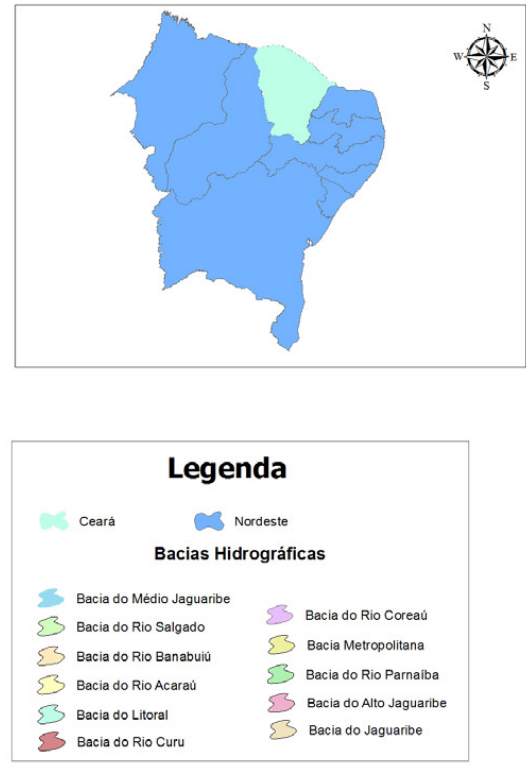

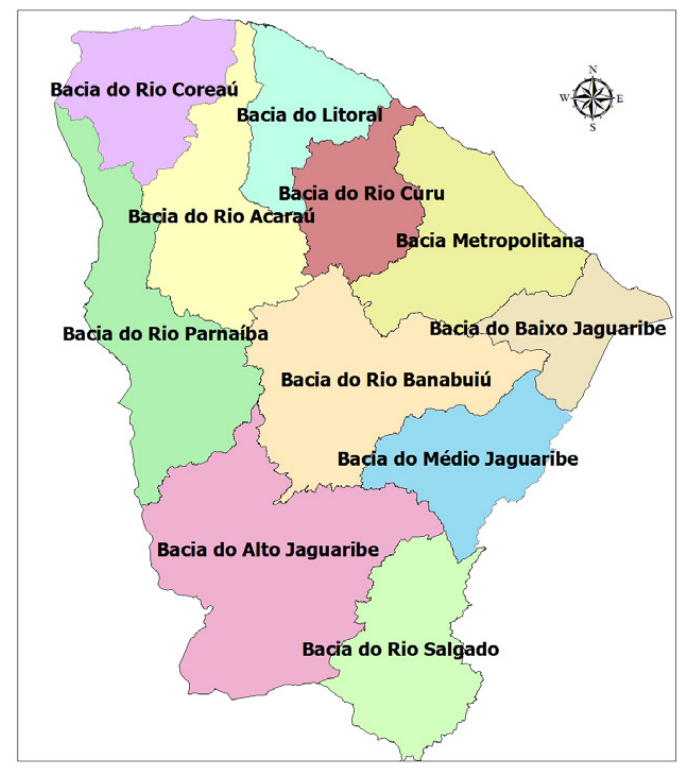

Adaptado de FUNCEME

Figura 3 - Bacias hidrográficas como unidades de planejamento - Estado do Ceará

É importante sublinhar que o PROGERIH é articulado pelo Conselho Estadual de Recursos Hídricos (COGEHR), Fundação Cearense de Meteorologia (Funceme) e a Superintendência de Obras Hídricas (SOHIDRA), que buscam recursos e fomentos para o desenvolvimento de obras hídricas que obedecem à lógica de seletividade do espaço com 
estruturação produtiva a partir, preferencialmente, da agroindústria para exportação. Em linhas gerais, cabe referenciar a definição e caracterização das principais funções com as respectivas subfunções em termos de gestão, oferta e preservação das águas no Ceará, onde pode ser percebida a centralidade da gestão de bacias hidrográficas como ponto de partida a um plano de gerenciamento de recursos hídricos (Figura 4).

No contexto dos usos múltiplos das águas na mancha semiárida nordestina, no geral, e em particular no Ceará, destaca-se a política de construção de barragens, denominadas regionalmente de açudes. Segundo Sampaio (2005), o Ceará concentra a maior quantidade de reservatórios de água do país, porém não representa ainda a solução para o problema da seca no Estado. Assim é que pelas condições edafoclimáticas e estuarinas, favorecedoras de acumulação natural de água, os baixos cursos das bacias - com destaque ao conjunto de nove bacias que formam a Bacia Metropolitana - concentram menores quantidades de açudes que os sertões, porém sofrem mais com problemas de contaminação das coleções hídricas. Na grande maioria dos casos, os trabalhadores do campo labutam com a escassez relativa da água, enquanto ilhas de prosperidade, atreladas ao capital privado, vivem do agronegócio (com destaque a pólos de irrigação e à carcinicultura). Prova disso é a política de gestão dos recursos hídricos, com destaque para a política da açudagem, onde os 126 maiores equipamentos são controlados pelo poder público estadual do Ceará através da Companhia de Gestão de Recursos Hídricos - COGEHR (2003) -, e federal (DNOCS) (Tabela 3), nas bacias mostradas na Figura 3. 


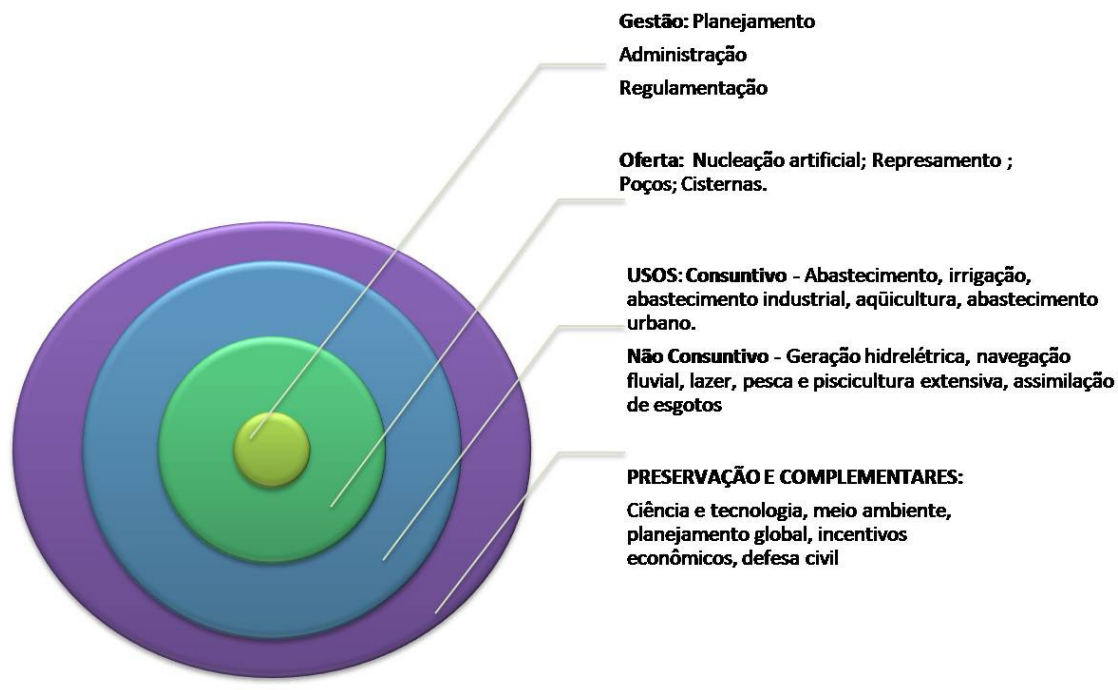

Figura 4 - Sistema de gestão de água e demais sistemas, a partir do Plano de Recursos Hídricos do Ceará de 1992. Fonte: Campos et al., (2001).

O sistema de barramentos enfrenta problemas com relação ao seu uso ótimo no contexto hidroclimático semiárido (alta evaporação e salinidade), produz modificações ambientais à montante ou à jusante das barragens e, de pronto, altera o ciclo hidrológico. Contudo, cabe ressalvar, que muito do que se debate hoje sobre o abastecimento de água no Nordeste, mormente nos estados setentrionais do Ceará, Rio Grande do Norte, Paraíba e Pernambuco, concentra-se na conveniência, ou não, de promover a transposição nas águas do São Francisco, questão polêmica e até o momento não consensual cuja problemática foge ao escopo desse ensaio.

\begin{tabular}{|l||c||c||c||}
\hline \multicolumn{1}{|c||}{$\begin{array}{c}\text { Bacias } \\
\text { Hidrográficas }\end{array}$} & Açudes & $\begin{array}{c}\text { Capacidade de } \\
\text { armazenamento }\left(\mathbf{m}^{3}\right)\end{array}$ & $\begin{array}{c}\text { Volume armazenado } \\
\left(\mathbf{m}^{3}\right) \text {, em fins de } \\
\text { quadra chuvosa } \\
(\mathbf{1 2} / \mathbf{0 7} / \mathbf{2 0 0 5})\end{array}$ \\
\hline \hline $\begin{array}{l}\text { Jaguraibe (sub- } \\
\text { bacias): }\end{array}$ & - & - & - \\
\cline { 2 - 4 } & 18 & 2.792 .563 .000 & $71,7 \%$ \\
\hline $\begin{array}{l}\text { Alto Jaguaribe } \\
\text { Salgado } \\
\text { Banabuiú }\end{array}$ & 13 & 447.410 .000 & $66,5 \%$ \\
\hline
\end{tabular}




\begin{tabular}{|c|c|c|c|}
\hline \multirow[t]{2}{*}{$\begin{array}{l}\text { Médio Jaguaribe } \\
\text { Baixo Jaguaribe }\end{array}$} & 13 & 6.860 .905 .600 & $64,8 \%$ \\
\hline & 1 & 24.000 .000 & $70,8 \%$ \\
\hline Acaraú & 12 & 1.443 .763 .000 & $76,7 \%$ \\
\hline Coreaú & 8 & 297.090 .000 & $78,3 \%$ \\
\hline Parnaíba & 9 & 673.840 .000 & $86,0 \%$ \\
\hline Metropolitana & 14 & 1.325 .344 .000 & $71,5 \%$ \\
\hline Litoral & 7 & 98.290 .000 & $66,3 \%$ \\
\hline Curu & 13 & 1.068 .355 .00 & $65,5 \%$ \\
\hline Total Estadual & 126 & 17.787.469.000 & 68,9 \\
\hline
\end{tabular}

Tabela 3 - Ceará: potencial de águas acumulados em reservatórios/açudes. Fonte. Elaborado a partir de Boletim informativo da COGEHR, 2005.

Considerando que a Gestão de bacias no Ceará seja a mais bem sucedida na história hídrica recente do Nordeste, no geral, e na Bacia do Atlântico Nordeste, em particular, não se pode perder de vista os diversos e complexos ambientais que acometem a bacias de drenagem. Portanto, os usos múltiplos dos recursos hídricos causam problemas ambientais de diversas etiologias, alhures e algures. Nesse contexto, para Derisio (2000) e Nascimento (2011), enquanto a grande maioria dos recursos naturais dispostos ao alcance das sociedades desaparece com o uso, as formas de utilização da água produzem alterações que repercutem sobremaneira nos seus aspectos quantitativos e qualitativos. Deste modo, dentre os principais agentes de poluição hídrica com sérias repercussões sobre a higidez dos recursos hídricos e, portanto, da qualidade ambiental, observa-se:

Esgotos domésticos: principais introdutores de compostos orgânicos biodegradáveis nos ecossistemas aquáticos através das águas servidas;

$\checkmark \quad$ Águas servidas dos trabalhos agropecuários e de abatedouros: os herbicidas, fertilizantes, pesticidas, agrotóxicos e defensivos agrícolas em geral, além de dejetos lavados de matadouros públicos e privados podem ser transportados pelas águas da chuva ou infiltrarem-se no subsolo, 
Despejos industriais e agroindustriais: principalmente provocados pelas olarias, são lançados a céu aberto, incorporando-se à rede de drenagem quando não são diretamente despejados in natura nas coleções d'água. No litoral, a carcinicultura lança milhares de litros de água contaminada nos estuários. No geral, podem variar conforme o porte da indústria/agroindústria de fruticultura e de cana-de-açúcar, em composição e volume;

Deficiência na coleta sistemática de lixo e ausência de aterros sanitários: parte do lixo produzido é depositado a céu aberto - por vezes, próximos aos veios fluviais e terrenos mais permoporosos. A deposição de lixo nos terraços mais baixos facilita a ação do chorume, induzindo à percolação para as águas superficiais e subterrâneas de: colóides, excesso de nitrogênio, hidrocarbonetos, metais pesados, fósforo, só para citar os mais nocivos. Um subproduto altamente tóxico que é comum na produção das cerâmicas e olarias é o cádmio;

Águas urbanas de escoamento superficial: não recebem a devida atenção e podem se constituir em um sério foco de poluição hídrica no momento em que, gravitacionalmente, são transportados detritos e volumes poluentes de toda sorte. Esse tipo de poluição pode provocar o aumento de incidência de doenças de veiculação hídrica, como a malária, mal de chagas, febre amarela, febre tifóide, tracoma, escabiose, lepra, conjuntivite, entre outras. Pode, ainda, elevar o teor de matéria orgânica nos lençóis subterrâneos e coleções d'água de superfície, tornando a qualidade da água imprópria para usos múltiplos;

Devido aos problemas sanitários das diversas bacias, às temperaturas elevadas e à diminuição da quantidade dos corpos hídricos no segundo semestre de cada ano -aliado à deposição de dejetos e aos hábitos da população - as chances de surgimento de enfermidades vinculadas à água exigem maiores cuidados pelas autoridades competentes. Além dos problemas de saúde humana, a contaminação das águas afeta a qualidade e a diversidade biológica, enquanto a atividade pesqueira fica comprometida e os usos das águas voltados às atividades recreativas e turísticas são afetadas negativamente. 


\section{Conflitos decorrentes dos usos múltiplos dos recursos hídricos}

Pelos usos múltiplos dos recursos hídricos, tais como pesca, recreação e contato primário, dessedentação de animais, diluição de dejetos, abastecimento público e irrigação ou uso residencial (populações carentes), ocorrem perdas na adução, no tratamento, na rede de distribuição e nos próprios domicílios, além dos eventuais desperdícios nos pontos de tratamento. Ocorrem usos potencialmente competitivos se a água alocada para irrigação competir com água para abastecimento de barragens tomadas a montante desta. Há usos complementares, como os feitos pela navegação, piscicultura, lazer ou controle de cheias; há usos que competem entre si, vinculados e competitivos, cujos exemplos são o abastecimento humano e a diluição de dejetos; e usos concomitantemente complementares dependentes e competitivos, são assim a irrigação e a geração de energia destinada a mover bombas de irrigação, como lembra Christofidis (2002), ratificado por Nascimento (2011).

Todavia, em virtude principalmente das formas de ocupação da terra, das atividades econômicas desenvolvidas e do acesso e uso dos recursos hídricos, em face da lógica global de acumulação do capital por meio do desenvolvimento desigual e combinado, diversos conflitos podem ser desenvolvidos. Deste modo, conflitos entre especulação imobiliária $\mathrm{x}$ comunidades tradicionais, pequenos produtores $\mathrm{x}$ (agro) indústria, mineração x turismo e lazer, unidades de conservação x turismo e lazer, preservação $\mathrm{x}$ atividades produtivas, urbanização $\mathrm{x}$ turismo, podem ser verificados ao longo das paisagens que compõem as sub-bacias da Bacia do Atlântico Nordeste, tais como: Acaraú-Coreaú $\left(30.500 \mathrm{~km}^{2}\right)$ e Jaguaribe $\left(72.000 \mathrm{~km}^{2}\right)$ - CE; Piranhas-Açu $\left(44.100 \mathrm{~km}^{2}\right)$ - RN; Bacia Oriental da Paraíba (23.760 km²); Bacia Oriental de Pernambuco (25.300 km²); Bacias Alagoanas $\left(17.100 \mathrm{~km}^{2}\right)$; e São Francisco $\left(487.000 \mathrm{~km}^{2}\right)$, para citar alguns exemplos encontrados.

Christofidis (2002) acredita que devem-se evitar os litígios (atuais e futuros) para que se alcancemr os usos conjuntivos associados aos partilhados dos recursos hídricos, definindo prioridades e eliminando os riscos de conflitos pelo uso da água. É preciso adequar o domínio dos usos e usuários da água, suas funções, categorização e escala de necessidades. Sem isso, não haverá melhoria nos índices de mensuração da qualidade de vida da população local e contígua.

Esses aspectos concernentes aos recursos hídricos foram mitigados no Quadro 4, denotando os usos, funções e utilizadores do produto água associados a aspectos de imprescindibilidade, possibilidade de substituição 
e efeitos a jusante. Ademais, serve como parâmetro comparativo ou norteador para gestão dos recursos naturais no Nordeste seco.

\section{Considerações Finais}

Tendo em vista as contingências ambientais deflagradas no Nordeste seco, a maior parte de suas bacias hidrográficas têm as quantidades e qualidades de suas águas, paulatinamente, reduzidas no tempo e no espaço. Além do que, os recursos naturais que ajudam a compor suas paisagens rústicas estão explorados e exauridos, sobretudo por falta de ações proativas do poder público e outros agentes estratégicos à ordenação do território, em face de vulnerabilidade às secas e pauperização da vida nos assentamentos humanos, principalmente os sertanejos.

Faz-se necessário e imprescindível o desenvolvimento de um plano de ação integrado, baseado na unidade da bacia hidrográfica através do envolvimento de agentes públicos, setor empresarial e da sociedade civil organizada em associações, considerando-se as leis ambientais e a realidade local de cada bacia. A par dessas questões, considerando as bacias hidrográficas como unidade de gestão e planejamento geoambiental, como outrora foi enfatizado, dentre outras estratégias e ações que podem ser ventiladas no domínio ambiental, propõe-se o desenvolvimento de trabalhos protecionistas das mesmas. Assim, a qualidade ambiental e de vida das populações podem ser otimizadas a partir de uma convivência com o fenômeno das secas no semiárido mais povoado do mundo, o brasileiro.

A gestão ambiental dos recursos hídricos, discutindo um modelo de desenvolvimento sustentado que não seja técnico nem polarizado para as bacias do Nordeste, principalmente em seu domínio semiárido, materializase como inerente ao seu processo de desenvolvimento econômico, social e de harmonia ambiental regional. Inicialmente, essa discussão perpassa pelo entendimento de detalhes das condições de semiaridez regional no contexto tropical, seguido pelo entendimento da consideração da bacia hidrográfica como âncora de desenvolvimento territorial, por constituir-se uma unidade da realidade ambiental para pesquisas interdisciplinares. 


\begin{tabular}{|c|c|c|c|c|c|}
\hline Usos & Funções & Utilizador final/associado & $\begin{array}{l}\text { Imprescindi } \\
\text { bilidade (I) }\end{array}$ & $\begin{array}{l}\text { Possibilidade } \\
\text { de substituição } \\
\text { (S) }\end{array}$ & $\begin{array}{c}\text { Efeito a } \\
\text { jusante } \\
\text { (J) }\end{array}$ \\
\hline $\begin{array}{c}\text { Bebida e } \\
\text { alimentação }\end{array}$ & Biológica/consumo & $\begin{array}{c}\text { Homem/entidade } \\
\text { concessionária, empresas de } \\
\text { águas minerais, } \\
\text { Animal/agropecuarista; } \\
\text { Fauna/meio ambiente, } \\
\text { Cultivos/irrigantes }\end{array}$ & $5,2,5,5$ & $\mathrm{~B}$ & $(-)$ \\
\hline Higiene/Limpeza & Condução/diluição/solvente & Homem/entidade concessionária & 5 & $\mathrm{~B}$ & $(-)$ \\
\hline Higiene/Limpeza & Condução/diluição/solvente & Animal /agropecuarista & 5 & $\mathrm{~B}$ & $(-)$ \\
\hline Higiene/Limpeza & Condução/diluição/solvente & $\begin{array}{c}\text { Homem/produtor } \\
\text { Industrial/agroindústria }\end{array}$ & 4 & $\mathrm{C}$ & $(-)$ \\
\hline $\begin{array}{c}\text { Produtor } \\
\text { industrial/agroind } \\
\text { ustrial }\end{array}$ & $\begin{array}{l}\text { Uso da água no } \\
\text { processamento/meio de } \\
\text { produção }\end{array}$ & $\begin{array}{l}\text { Homem/produtor/industrial/agro- } \\
\text { industrial }\end{array}$ & 3 & $\mathrm{~B} / \mathrm{C}$ & $(-)$ \\
\hline Navegação & Transporte/turismo & Homem/empresários do turismo & 1 & $\mathrm{~B}$ & $(0)(-)$ \\
\hline Refrigeração & Temperatura/conservação & Indústria/agroindústria/comércio & 2 & $\mathrm{~B}$ & $(-)$ \\
\hline $\begin{array}{c}\text { Sustentação à } \\
\text { vida }\end{array}$ & Consumo (biológica) & Biodiversidade/humano & 5 & B & $(-)$ \\
\hline Lazer e Desporte & Suporte/estética & Homem/clubes/pesque e pague & 3 & $\mathrm{~B}$ & $(-)$ \\
\hline $\begin{array}{l}\text { Destinação final } \\
\text { (rejeição) }\end{array}$ & Diluição/solvente & Homem/fauna e Flora & 5 & B & $(+)(-)$ \\
\hline
\end{tabular}

Quadro 4- Usos, funções e utilizadores do produto água associados a aspectos de imprescindibilidade, possibilidade de substituição e feitos a jusante na Bacia do Atlântico Nordeste

Obs: (I) indica a possibilidade existente com a tecnologia atual de alcançar a mesma finalidade com usos alternativos. A imprescindibilidade varia de um (mínima) à cinco (máxima); (S) Reflete a existência de outro produto que possa substituir o "produto água", total ou parcialmente, em algumas de suas funções. Adotou-se indicar se Existe Possibilidade (A), ou Não Existe (B) ou é Parcialmente substituível por algum outro produto (C); (J) Decorrentes da retirada de quantidade e/ou lançamento de resíduos, são indicados como Negativo (-), Positivos (+) ou nulos (0). Fonte: Adaptado de Frade e Alves (1991) in Christofidis (2002). 


\section{OS RECURSOS HÍDRICOS E O TRÓPICO SEMIÁRIDO NO BRASIL}

Resumo: Na discussão sobre a imprescindibilidade da água, os Trópicos e o Nordeste Semiárido Brasileiro foram tratados no presente texto. Para tanto, a bacia hidrográfica foi considerada como unidade ambiental de planejamento, de modo que ganhassem foco as de caráter intermitentes sazonais, como por exemplo a Bacia do Atlântico Nordeste. Não obstante, potencialidades hidrogeológicas, gestão de bacias hidrográficas e alterações ambientais, bem como conflitos decorrentes dos usos múltiplos dos recursos hídricos foram temas discutidos neste trabalho.

Palavras-chave: usos múltiplos e conflitos por Recursos hídricos, Trópico Semiárido Brasileiro, bacias hidrográficas.

\section{THE WATER RESOURCES AND THE TROPICS SEMIARID}

Abstract: The Northeastern Brazilian Semiarid Tropics and were treated in this text from the indispensability of the water element. By the time, the river basin was considered as a unit of environmental planning in order to earn the focus of intermittent seasonal character, as an example of the Atlantic North Basin. Nevertheless, hydrogeological potential, management watershed and environmental changes as well as conflicts arising from multiple uses of water resources issues were discussed in the paper.

Key-words: Multiple uses and conflicts for water resources, Semi-arid Tropics, river basins.

\section{BILIOGRAFIA}

AB'SABER, Aziz N. (1999) Sertões e Sertanejos: uma geografia humana sofrida. In Revista Estudos Avançados. Dossiê Nordeste Seco. 13 (36), São Paulo: Centro de Estudos Avançados, p. 7 - 59.

AYOADE, J. O. (2002) Introdução à Climatologia para os Trópicos. $8^{\mathrm{a}}$. Ed. Rio de Janeiro: Bertrand Brasil, p. 332.

CAMPOS, Nilson et al. (2001) Gestão de Águas: princípios e práticas. Porto Alegre: ABRH, pp.17-24.

BATCHELOR, C.H. \& WALLACE, J.S. (2001) Hydrological Process, Dryland Degradation and Integrated Catchment Resource Management. In: Desertification Control Bulletin: A Bulletin: of World Events In: the 
Control of Desertification, Restoration of Degrade Lands and Reforestation. Number 27. United Nations Environment Programme (UNEP), pp. 27-34.

BRASIL//Ministério do Meio Ambiente (MMA). (2004) Programa de Ação Nacional de Combate à Desertificação e Mitigação dos Efeitos da Seca, PAN-BRASIL. Edição Comemorativa dos 10 anos da Convenção das Nações Unidas de Combate à Desertificação e Mitigação dos Efeitos da Seca - CCD. Brasília: MMA, 225p.

COMPANHIA DE GESTÃO DOS RECURSOS HÍDRICOS DO CEARÁ (COGERH). (2003) Realização do cadastramento dos maiores açudes públicos e privados do Estado do Ceará, com geração de banco de dados. Relatório final. Vol. III. Bacia do Acaraú. Fortaleza: KL Serviço de Engenharia S/C Ltda, pp. 7-156.

CEARÁ/SECRETARIA DE RECURSOS HÍDRICOS - SRH. (1992) Plano Estadual de Recursos Hídricos. Fortaleza.

CHRISTOFIDIS, Demetrios. (2002) Considerações sobre conflitos e uso sustentável em recursos hídricos. In: THEODORO, Suzi (org.). Conflitos e uso sustentável dos recursos naturais. Rio de Janeiro: Graramon, pp. 1328.

CONTI, José B. \& Furlan, Sueli A. (1995) Geoecologia: o clima, os solos e a biota. In Ross, J. L. S. (org.). Geografia do Brasil. São Paulo: Edusp. pp. $67-208$.

A Geografia Física e as relações sociedade-natureza no mundo tropical. 1999 In Carlos, Ana F.A. (org.) Novos caminhos da Geografia. São Paulo: Contexto.

CPRM. Atlas dos recursos hídricos subterrâneos do Ceará. (1998) Fortaleza: CPRM.

CRUZ, Henryette D.; Coimbra, Roberto M.: Freitas, Marcos A.V. de. O estado das águas no Brasil: vulnerabilidade climática e Recursos Hídricos no Nordeste. [On line]. Maio de 2003. [cited 26.05.2003]. http://www. mma.gov.br/port/srh. 12p.

CUNHA, Sandra B. da. Bacias Hidrográficas. (2001) In: Cunha, S.B. da. e Guerra, A. J. T (org.). Geomorfologia do Brasil. $2^{\mathrm{a}}$ ed. Rio de Janeiro: Bertrand Brasil. p. 229-276. ISBN 85-286-0670-8. 
DERISIO, José, C. (2000) Introdução ao controle da poluição ambiental. .2 ed. São Paulo: Signus Ed.

EBISEMIJU, Fola S. (1989) The response of headwater stream channels to urbanization in the humid tropics. In: Hydrological Processes. Vol. 3. London, pp. 237-253.

FILHO, Joaquim G.C. (Org.). (1994) Projeto Áridas: uma estratégia de desenvolvimento sustentável para o Nordeste. GTII. Recursos Hídricos: II. 2 - Sustentabilidade do Desenvolvimento do Semiárido sob o ponto de vista dos Recursos Hídricos. Brasília, 102 p.

GONÇALVES, J. Y.B., Cordeiro, W., Holanda, C.H.N. (1984) Considerações sobre a captação de água subterrânea na Região Cristalina no semiárido cearense - uma alternativa. In Anais do $3^{\circ}$ Congresso Brasileiro de Águas Subterrâneas. (Anais 1). Fortaleza.

IPLANCE. Atlas do Ceará. (1997) CD Room. Fortaleza: Edições IPLANCE.

JATOBÁ, Lucivânio; LINS, Rachel C.; OLIVEIRA, José G. B. de e SOUZA, Marcos J. (1996) N. de. Condições Geo-ambientais do semiárido brasileiro. In Notas e Comunicações de Geografia. Série B: Textos didáticos $n^{\circ} 15$. Dept ${ }^{\circ}$ de Ciências Geográficas - UFPE, Recife - PE. MINISTÉRIO DA INTEGRAÇÃO NACIONAL. (2005) Relatório final. Grupo de trabalho interministerial para redelimitação do semi-árido nordestino e do polígono das secas. Brasília: Ministério da Integração Nacional, p.117.

MINISTÉRIO DO MEIO AMBIENTE (MMA)/PNMA. (1997) Plano de conservação da Bacia do Alto Paraguai, Programa Nacional do Meio ambiente. Brasília: MMA,. pp. 299-329.

NASCIMENTO, Flávio R. do. (2005) Degradação ambiental e desertificação no Nordeste Brasileiro: o contexto da bacia do rio AcaraúCeará. Qualificação de doutorado. UFF/PPGEO, Niterói, 331p.

- Categorização de usos múltiplos dos recursos hídricos e problemas ambientais. In Revista da Anpege, v. 7, n. 1, número especial. pp. 81-97, Goiânia: GO. 
PAULA, João A. de et al. (1997) Biodiversidade, população e economia: uma região de Mata Atlântica. Belo horizonte: UFMG/Cedeplar; ECMXC; PADCT/CIAMB.

RODRIGUES, Hugo. (1999) A gestão da água: discurso e prática no contexto cearense. In Amora, Z. B et al. O Ceará: enfoques geográficos. Fortaleza: FUNECE.

REBOUÇAS, Aldo. da C. (1997) Água na região Nordeste: desperdício e escassez. Revista Estudos Avançados 11(29): Edusp, São Paulo.

Água Doce no Mundo e no Brasil. (2002) In: Rebouças, A. da C.; Braga, B.; e Tundisi, J. G. (orgs.). Águas doces no Brasil: capital ecológico, uso e conservação. $2^{\mathrm{a}}$ edição. São Paulo: Escrituras Editora.

. (2002) Águas subterrâneas. In: Rebouças, A. da C.; Braga, B.; e Tundisi, J. G. (orgs.). Águas doces no Brasil: capital ecológico, uso e conservação. 2a edição. São Paulo: Escrituras Editora, pp. 151-199.

RODRIGUEZ, J. M. M \& SILVA, E. V. da. (2002) "A classificação das paisagens a partir de uma visão geossistêmica". In: Mercator - Revista do Dept $^{\circ}$ de Geografia/UFC. Fortaleza-CE: Desk Copy. Ano I, n ${ }^{\circ} 01$, pp. 95112.

SAMPAIO, Levi F. (2005) As águas, a seca e o estado. IN: Silva, José B. da S.et al., (orgs.). Ceará: um novo olhar geográfico. Fortaleza: Edições Demócrito Rocha. pp. 463-476.

SOUZA, Marcos J. N. (2000) Bases geoambientais e esboço do zoneamento geoambiental do Estado do Ceará. In: LIMA, Luiz. C. (Org.) Compartimentação territorial e gestão regional do Ceará. Fortaleza: FUNCEME, pp. 6-105.

VIEIRA, Vicente P.P.B. (2002) Água Doce no Semiárido. In: Águas Doces no Brasil: capital ecológico, uso e conservação. $2^{a}$ edição. São Paulo: Escrituras Editora, pp. 507-530.

Data de submissão: 25/10/12 Data de aprovação: 04/03/13 